\title{
Exposure to house dust mite allergens and the clinical activity of asthma
}

\author{
Adnan Custovic, MD, ${ }^{a}$ Simon C. O. Taggart, MRCP, ${ }^{a}$ \\ Helen C. Francis, BSc, ${ }^{a}$ Martin D. Chapman, PhD, ${ }^{b}$ and \\ Ashley Woodcock, FRCPa Manchester, England, and Charlottesville, Va.
}

\begin{abstract}
Background: House dust mite allergens play an important role in inducing IgE-mediated sensitization and the development of bronchial hyperresponsiveness (BHR) and asthma. This study investigated the relationship between mite allergen exposure and the clinical activity and severity of asthma.

Methods: Nonsmoking adult patients with asthma $(\mathrm{n}=53)$ were randomly recruited from the asthma registry of two large family practitioner surgeries. Each participant underwent skin testing with common inhalant allergens, a methacholine bronchoprovocation test, and pulmonary function testing on up to 3 separate occasions over a 4-week period. BHR was expressed both as $P D_{20}$ and dose-response ratio (DRR), and the patients with $P D_{20}$ of less than $12.25 \mu \mathrm{mol}$ methacholine were classified as methacholine reactors. Patients were also asked to record peak expiratory flow rate (PEFR) values at 2-hour intervals during waking hours for 1 month. Daily PEFR variability was calculated as amplitude percent mean. Dust samples were collected by vacuuming bedding, bedroom carpets and mattresses. In addition, in the homes of 32 subjects with positive skin test responses to mites, airborne samples were taken overnight for 8 hours with a personal sampler attached to each subject's pillow. Der $p 1$ and Der $p 2$ levels were determined by a two-site monoclonal antibody-based ELISA.

Results: No difference in mite allergen exposure was found between subjects who were sensitive to mites and those who were not. However, mite-sensitive methacholine reactors were exposed to significantly higher concentrations of Der $p 1$ in beds than mite-sensitive methacholine nonreactors $(13.2 \mu \mathrm{g} / \mathrm{gm}$ and $1.45 \mu \mathrm{g} / \mathrm{gm}$, respectively; $\mathrm{p}<0.02)$. Der $p 1$ and Der $p 2$ were undetectable in 30 of 32 airbome samples. In mite-sensitive patients both Der $p 1$ and Der $p 2$ in beds significantly correlated with BHR $\left(P D_{20}: \mathrm{r}=-0.49, D R R, \mathrm{r}=0.49 ; P D_{20}: \mathrm{r}=-0.46, D R R\right.$ : $\mathrm{r}=0.43)$ and amplitude percent mean PEFR $(\mathrm{r}=0.38, \mathrm{r}=0.41)$ for Der $p 1$ and Der $p 2$, respectively. There was a significant negative correlation between exposure to Der $p 1$ and percent predicted $F E V_{1}(\mathrm{r}=-0.43)$. The correlation between Der $p 2$ and percent predicted $F E V_{1} j u s t$ failed to reach a significant level but showed a clear trend $(\mathrm{r}=-0.35, \mathrm{p}=0.068)$.

Conclusions: Clinical activity and severity of asthma (measured by the level of BHR, PEFR variability, and percent predicted $F E V_{1}$ ) in mite-sensitive patients is related to exposure to mite allergens in the dust reservoir, with levels in bed being an important indicator that correlated with disease activity. (J Allergy Clin Immunol 1996;98:64-72.)
\end{abstract}

Key words: Asthma, house dust mite allergen, airborne, reservoir, bronchial hyperreactivity

From aNorth West Lung Centre, Wythenshawe Hospital, Manchester, England; and ${ }^{\mathrm{b}}$ Asthma and Allergic Diseases Center, University of Virginia Health Sciences Center, Charlottesville.

Supported in part by Fondation Lancardis and National Institutes of Health grants AI 32557 and AI 34607.

Received for publication Mar. 21, 1995; revised Sept. 26, 1995; accepted for publication Sept. 28, 1995.

Reprint requests: Adnan Custovic, MD, North West Lung Centre, Wythenshawe Hospital, Southmoor Rd., Manchester, M23 9LT, U.K.

Copyright $(\mathcal{C} 1996$ by Mosby-Year Book, Inc.

$0091-6749 / 96 \$ 5.00+0 \quad \mathbf{1} / \mathbf{1} / \mathbf{6 9 6 0 7}$
Evidence strongly suggests that the prevalence and severity of asthma is increasing, especially in children, in spite of the availability of effective treatment. ${ }^{1}$ House dust mite allergens are a major cause of asthma worldwide, and $45 \%$ to $85 \%$ of patients with asthma in the United Kingdom show skin test reactivity to mites, as compared with $5 \%$ to $30 \%$ in the general population. ${ }^{2}$ The importance of early exposure to mite allergen in primary sensitization has been suggested by recent studies. Household exposure to levels of Der p 1 greater than $2 \mu \mathrm{g} / \mathrm{gm}$ of dust 


\begin{tabular}{|rl|}
\hline & \\
Abbreviations used \\
BHR: & Bronchial hyperresponsiveness \\
CL: & Confidence limits \\
DRR: & Dose-response ratio \\
GM: & Geometric mean \\
PEFR: & Peak expiratory flow rate \\
\hline
\end{tabular}

in carpets and bedding during infancy is associated with increased prevalence of positive skin test results and increased levels of specific $\operatorname{IgE}$ to mites by the age of 5 years. ${ }^{3}$ Furthermore, in an infant cohort prospectively followed up from birth, Der p 1 levels of greater than $10 \mu \mathrm{g} / \mathrm{gm}$ of dust measured in infancy were associated with 4.8-fold relative risk of developing asthma at the age of 11 years. ${ }^{4}$ Studies from Papua, New Guinea, and other communities newly exposed to mites suggest that increased exposure to mite allergens is followed by increased prevalence of asthma. ${ }^{5}$ Mite-sensitive asthma is less common at altitudes with low humidity and very few mites. $^{6,7}$ There is a quantitative relationship between cumulative exposure to mite allergens and initial sensitization. ${ }^{8}$ The development of asthma can be considered to consist of several distinct but probably related processes. First, exposure of the genetically predisposed individual to a critical level of allergen may result in sensitization, then further exposure of the sensitized individual leads to the development of airway inflammation and bronchial hyperresponsiveness (BHR). ${ }^{9}$

This study investigated the relationship between ongoing mite allergen exposure and asthma severity. Prevalence rates are one way of measuring the magnitude and dimension of a particular disease. Severity and clinical activity also provide an important measure of the impact of the disease on patients' lives, the health care system, and the amount of medical care that an individual patient requires. In the case of asthma, several studies have suggested that these features may be related to allergen exposure. ${ }^{10-12}$ This study investigated the relationship between exposure to the major house dust mite allergens (Dermatophagoides spp. Group 1 and Group 2) and the severity and clinical activity of asthma as defined by the objective parameters of BHR, peak expiratory flow rate (PEFR) variability, and pulmonary function testing.

\section{METHODS Subjects}

For screening and entry into the study, patients were recruited from asthma registers in two large family practitioner surgeries. Subjects were selected by using a random one-in-four sample. A total of 200 patients was screened. Patients with a confirmed diagnosis of asthma were eligible to enter the study if they met the following criteria: (1) nonsmoking adults between the ages of 16 and 60 years; (2) receiving treatment with short-acting bronchodilators alone or in combination with inhaled steroids, long-acting $\beta_{2}$-agonists, sodium cromoglycate, and/or nedocromil sodium; (3) no changes in asthma medication in the previous 3 months; (4) free of respiratory tract infection within the past 4 weeks. Before entry, each subject received a full explanation of the study and signed a consent form. The study protocol was approved by the ethics committees of Halton Borough and University Hospitals of South Manchester. Subjects were requested to withhold all bronchodilator medication for 6 hours (short-acting) or 24 hours (long-acting) before each study visit. Other asthma treatment was continued throughout the study. Each participant underwent the following procedures: (1) skin prick testing with common inhalant allergens (D. pteronyssinus, cat, mixed grasses, and trees; E. Merck Ltd., Alton, U.K.) (wheal diameter at least $3 \mathrm{~mm}$ greater than negative control considered a positive response); (2) bronchial provocation testing with methacholine to measure BHR; (3) pulmonary function testing on up to 3 separate occasions over the period of 4 weeks (individual measurements being at least 1 week apart); (4) recording of PEFR values at 2 -hour intervals during waking hours for a total of 1 calendar month; (5) home visits for questionnaires and collection of domestic dust samples within 2 weeks of bronchial provocation test; (6) recording of symptom scores and bronchodilator use once daily (in the evening) throughout the study period on a diary card; and (7) airborne sampling in homes of patients with positive skin test responses to house dust mites.

\section{Bronchial challenge and pulmonary function testing}

Subjects underwent a methacholine bronchial challenge with Yan's technique. ${ }^{13}$ Baseline pulmonary function was recorded on a dry bellows spirometer (Vitalograph, Buckinghamshire, U.K.) as the best of three efforts, with the two highest being within $5 \%$ of one another. Subjects with a baseline $\mathrm{FEV}_{1}$ of less than $50 \%$ of the predicted value were excluded from further study. Three inhalations of normal saline solution were then administered, and a postsaline $\mathrm{FEV}_{1}$ was measured after 1 minute. Starting from $0.045 \mu \mathrm{mol}$ of methacholine, sequential doubling doses were then administered from individually calibrated, hand-held De Vilbiss No. 40 glass nebulizers (De Vilbiss, Somerset, U.K.) to a maximum of 12.25 $\mu \mathrm{mol}$ methacholine or until $\mathrm{FEV}_{1}$ fell by $20 \%$ or more from baseline. A positive response was defined as the 
cumulative dose of methacholine causing a 20\% drop in the postsaline $F E V_{1}$. This was estimated by using linear interpolation between log doses and expressed as $\mathrm{PD}_{20}$. The results of bronchial challenge testing were further expressed as dose-response ratio. Patients with $\mathrm{PD}_{20}$ of less than $12.25 \mu \mathrm{mol}$ methacholine were classified as methacholine reactors, and those with $\mathrm{PD}_{20}$ greater than $12.25 \mu \mathrm{mol}$ were classified as methacholine nonreactors.

For the analysis of pulmonary function testing (percent predicted $F E V_{1}$ ), the mean of all of the best of three efforts recorded at individual measurements was used.

\section{PEFR measurement}

Patients were supplied with diary cards and Peak Flow Meters (Clement Clarke International Ltd., Essex, U.K.) and were advised not to record PEFR for 6 hours after use of short-acting bronchodilator medication. PEFR records were considered satisfactory if at least three readings per day were recorded on at least 14 days. Daily PEFR variability was calculated as amplitude percent mean $^{15}$ :

$$
\frac{\text { Highest }- \text { lowest PEFR value }}{\text { Mean }} \times 100
$$

\section{Symptom scores and bronchodilator use}

Subjects were asked to record the presence, frequency, and severity of wheeze, breathlessness, and cough and the number of puffs of bronchodilators used. Daily aggregate symptom scores were averaged over a 4-week period. The scores were positively skewed and included many zero values. For this reason, the aggregate symptom scores were square root-transformed for analysis.

\section{Dust sample collection, extraction, and allergen assay}

Dust samples were collected by using a Medivac dust sampler (Medivac Plc., Wilmslow, U.K.) with an airflow rate of $45 \mathrm{~L} / \mathrm{sec}$ through a $355 \mu \mathrm{m}$ diameter mesh screen on a $5 \mu \mathrm{m}$ vinyl filter (Plastok Associates Ltd., Wirral, U.K.), thus enabling collection of fine dust samples. Bedding (pillows and quilt) and a $1 \mathrm{~m}^{2}$ area of bedroom carpet and mattress were vacuumed for 2 minutes. Dust samples were stored at $4^{\circ} \mathrm{C}$ until extracted. Each sample was weighed, and $100 \mathrm{mg}$ of fine dust was extracted by rotation for 2 hours at room temperature with $2 \mathrm{ml}$ of borate-buffered saline with $0.1 \%$ Tween-20, $\mathrm{pH} 8.0$, and then centrifuged for 20 minutes at $2500 \mathrm{rpm}$ at $4^{\circ} \mathrm{C}$. Supernatants were stored at $-20^{\circ} \mathrm{C}$ for future analysis of allergen content.

In addition, airborne samples were collected from the homes of 32 subjects with positive skin test responses to mites. Samples were taken overnight ( 8 hours) with a Casella AFC 123 personal sampler $(2 \mathrm{~L} / \mathrm{min}$; Casella Ltd., London, U.K.) attached to the pillow. Filters were extracted in $1 \mathrm{ml}$ of $1 \%$ bovine serum albumin in phosphate-buffered saline-Tween-20 overnight, filtered
(0.2 $\mu \mathrm{m}$; Whatman Inc., Fairfield, N.J.) and stored at $-20^{\circ} \mathrm{C}$ for future analysis of allergen content. Der $\mathrm{p} 1$ and Der $\mathrm{p} 2$ were measured with a two-site monoclonal antibody-based ELISA. ${ }^{16,17}$ Dust samples with Der $\mathrm{p} 1$ and Der $\mathrm{p} 2$ levels below the lower limit of detection of the assays were assigned a value of $100 \mathrm{ng} / \mathrm{gm}$ for further analysis, corresponding to the lower limit of detection of the assays.

\section{Statistical analysis}

Der p 1, Der p 2, dose-response ratio (DRR), and amplitude percent mean data were found to follow a log-normal distribution; the results are thus reported as geometric means (GMs) and 95\% confidence limits (CL). The relationships between different variables were investigated by using linear regression. Differences in the level of exposure to mite allergen between the groups were investigated by using Student's $t$ test. Statistical significance was set at a conventional $5 \%$ level.

\section{RESULTS Demography}

Fifty-three patients fulfilled the inclusion criteria and agreed to take part in the study (17 men and 36 women; mean age, 40.5 years). Those subjects not wishing to take part did not differ in either sex or age. Two subjects had infective exacerbations of their asthma during the course of the study, and their results were excluded from the analysis of asthma severity. Of the 51 subjects who successfully completed the study, three had a baseline $\mathrm{FEV}_{1}$ of less than $50 \%$ predicted for age and gender on 3 separate occasions (each with $>15 \%$ reversibility) and therefore did not undergo bronchial challenge testing. Of the 48 participants who underwent methacholine challenge, $16(33 \%)$ had $\mathrm{PD}_{20}$ greater than $12.25 \mu \mathrm{mol}$ methacholine. Methacholine nonreactors were assigned a value of $12.25 \mu \mathrm{mol}$ for further analysis. The results of bronchial challenge testing were further expressed as DRR because a DRR value can be calculated for all subjects, however small their response to the challenge agent. Forty-eight satisfactorily completed PEFR records were analyzed, with an average of 23.7 days with at least four PEFR readings. The measures of disease activity in the studied group of 51 patients were as follows: $\mathrm{PD}_{20}, \mathrm{GM}=$ 2.63 (95\% CL $=1.71-4.06) \mu \mathrm{mol}$ methacholine; amplitude percent mean PEFR, GM $=10.48 \%$ (95\% CL = 9.16-11.99); percent predicted $\mathrm{FEV}_{1}$, mean $=88.74 \%$ (95\% CL 82.94-94.53).

Thirty-nine of 53 patients who were enrolled in the study $(73.6 \%)$ had a positive skin test response to at least one of the allergens tested; $32(60.4 \%)$ had a positive response to mites. Twenty-five sub- 


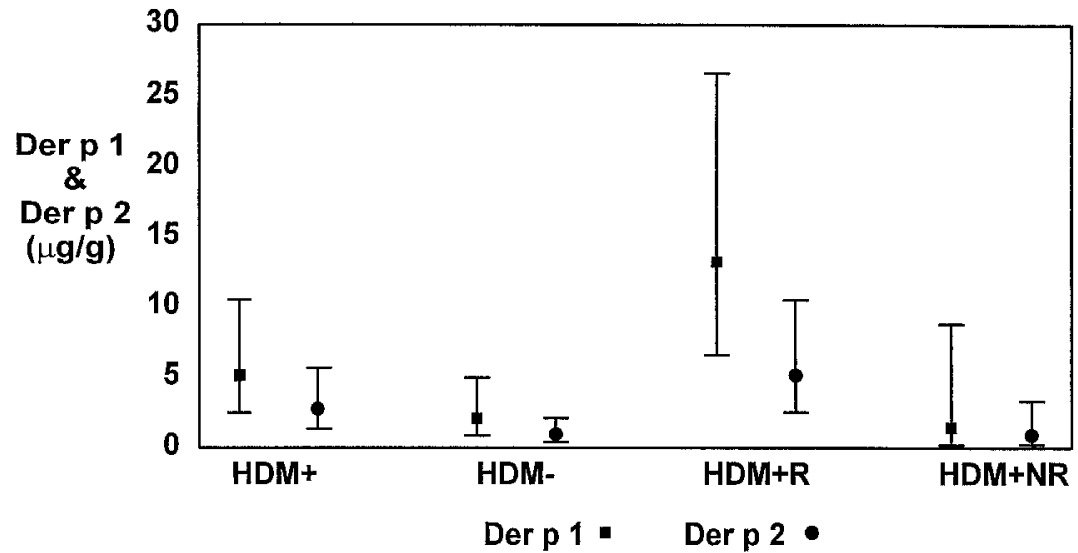

FIG. 1. Concentrations of mite allergens Der $p 1$ and Der $p 2$ in mattresses in different subgroups of patients (GM and $95 \% \mathrm{CL}$ ). HDM +, Patients with positive skin test responses to mites; HDM -, patients with negative skin test responses to mites; $H D M+R$, mite-positive methacholine reactors; $H D M+N R$, mite-positive methacholine nonreactors.

jects had positive skin test responses to three or more allergens, eight had positive responses to two allergens, and six had positive responses to one allergen only.

\section{House dust mite allergen exposure}

Mean Der $\mathrm{p} 1$ concentrations in house dust samples from the homes of 53 subjects who were enrolled in the study were $3.6,1.2$, and $4.4 \mu \mathrm{g} / \mathrm{gm}$ in mattresses, bedroom carpets, and bedding, respectively. Although there was a highly significant correlation between Der $\mathrm{p} 1$ in the mattresses and bedding $(r=0.68, p<0.001)$, occasionally high levels of Der $\mathrm{p} 1$ were found in bedding with low mattress levels and vice versa.

Fig. 1 shows the level of exposure to mite allergens Der p 1 and Der $\mathrm{p} 2$ in mattresses in different subgroups (mite-positive patients, mitenegative patients, mite-positive methacholine reactors, mite-positive methacholine nonreactors). No difference in the level of exposure was found between subjects with positive responses and those with negative responses to mites in either Der $\mathrm{p} 1$ or Der p $2(p>0.1)$. However, mite-positive methacholine reactors were exposed to a ninefold higher concentration of Der $\mathrm{p} 1$ and to sixfold higher concentrations of Der $\mathrm{p} 2$ than mitepositive methacholine nonreactors: $\mathrm{GM}=13.2$ $\mu \mathrm{g} / \mathrm{gm}(95 \% \mathrm{CL}=6.57-26.6)$ and $\mathrm{GM}=1.45$ $\mu \mathrm{g} / \mathrm{gm}(95 \% \mathrm{CL}=0.22-8.78), p<0.02 ; \mathrm{GM}=$ $5.2 \mu \mathrm{g} / \mathrm{gm}(95 \% \mathrm{CL}=2.54-10.51)$ and $\mathrm{GM}=0.87$ $\mu \mathrm{g} / \mathrm{gm}(95 \% \mathrm{CL}=0.23-3.33), p<0.05$ for Der $\mathrm{p} 1$ and Der $\mathrm{p} 2$, respectively.

There was an excellent correlation between Der p 1 and Der $\mathrm{p} 2$ values (Fig. 2) in all of the analyzed samples, with the GM levels of allergens being 2.54 $\mu \mathrm{g} / \mathrm{gm}(95 \% \mathrm{CL}, 1.79-3.6)$ and $1.34 \mu \mathrm{g} / \mathrm{gm}(95 \%$ $\mathrm{CL}, 0.97-1.84$ ) for Der $\mathrm{p} 1$ and Der $\mathrm{p} 2$, respectively, with a Der $\mathrm{p} 1$ to Der $\mathrm{p} 2$ ratio of 1.89:1.

\section{Airborne sampling}

To investigate the possibility that airborne allergen exposure was more relevant than the allergen concentration in reservoir dust, we used personal samplers to measure airborne exposure to Der $p 1$ and Der $\mathrm{p} 2$ in mite-sensitive subjects. Der $\mathrm{p} 1$ and Der p 2 were undetectable in 30 of $32(93.75 \%)$ airborne samples and barely detectable in two $(<4$ $\mathrm{ng} / \mathrm{ml}$; mean sample volume, $0.95 \mathrm{~m}^{3}$ ).

\section{Allergen exposure and disease activity}

Thirty-two subjects ( 13 men; mean age, 39 years) had positive skin test responses to mites. Of these, two experienced infective exacerbations of their asthma; one patient was a cat owner sensitized to both mites and cats and exposed to high levels of Fel $\mathrm{d} 1(793 \mu \mathrm{g} / \mathrm{gm}$ in the bedding dust and 38 $\mathrm{ng} / \mathrm{m}^{3}$ in the airborne sample collected overnight). The test results for these three patients were therefore excluded, because both viral infection and sensitization and exposure to high levels of cat allergen would be important confounding factors, thus leaving 29 patients eligible for the analysis.

All 29 subjects had pulmonary function testing on up to 3 separate occasions. Two patients had a baseline $\mathrm{FEV}_{1}$ of less than $50 \%$ of predicted value and therefore did not undergo bronchial challenge. The remaining 27 patients successfully completed bronchoprovocation testing (21 methacholine reactors). Two patients receiving treatment with a 


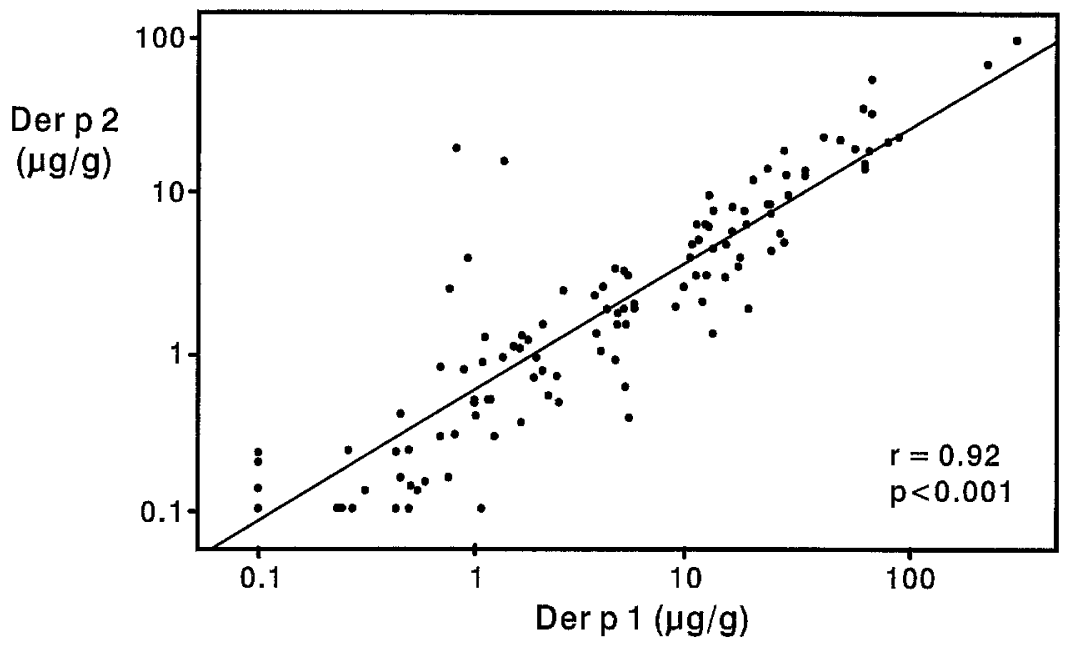

FIG. 2. Correlation between Der p 1 and Der $p 2$ concentrations in house dust samples.

long-acting $\beta_{2}$-agonist were excluded from the analysis of PEFR variability. The remaining 27 participants returned satisfactory PEFR diaries.

The measures of disease activity in mite-sensitive subjects who successfully completed at least one part of the study (bronchial challenge, pulmonary function testing, or PEFR diaries) were: $\mathrm{PD}_{20}, \mathrm{GM}=1.73 \mu \mathrm{mol}$ methacholine $(95 \% \mathrm{CL}=$ 0.90-3.44); amplitude percent mean PEFR, GM = $11.13 \%$ (95\% CL $=9.29-13.34)$; and percent predicted $\mathrm{FEV}_{1}$, mean $=86.24 \%(95 \% \mathrm{CL}=77.76$ 94.72); 21 subjects with negative skin test responses to mites did not differ significantly with respect to age, gender, or indices of disease activity.

There was a significant negative correlation between $\mathrm{PD}_{20}$ and Der $\mathrm{p} 1$ level in mattress dust (log-transformed data: $r=-0.46, p<0.025$ ). The association was strengthened when the highest level of Der $p 1$ in bed (mattress or bedding) was used as the index of personal exposure. Figs. 3 and 4 show the correlations between Der p 1 and Der p 2 in bedding and measures of disease activity. The results demonstrate:

- A significant negative correlation between exposure to group 1 and group 2 house dust mite allergens and $\mathrm{PD}_{20}(r=-0.49, p<0.01$ for Der $\mathrm{p} 1$ and $r=-0.46, p<0.02$ for Der p 2)

- A significant positive correlation between exposure to mite allergens and DRR $(r=0.49$, $p<0.01$ for Der $\mathrm{p} 1$ and $r=0.43, p<0.025$ for Der p 2)

- A significant positive correlation between exposure to mite allergens and amplitude per- cent mean PEFR $(r=0.38, p<0.05$ for Der p 1 and $r=0.41, p<0.05$ for Der p 2)

- A significant negative correlation between exposure to Der $\mathrm{p} 1$ and percent predicted $\mathrm{FEV}_{1}(r=-0.43, p<0.025)$.

The correlation between Der p 2 and percent predicted $\mathrm{FEV}_{1}$ just failed to reach a significant level but showed a clear trend $(r=-0.35, p=$ 0.068 ).

The correlation between the measures of disease activity and Der p 1 concentration in bedroom carpets was not significant $\left(\mathrm{PD}_{20}, r=0.01\right.$; DRR, $r=0.05$; amplitude percent mean PEFR, $r=0.07$; percent predicted $\mathrm{FEV}_{1}, r=0.30$ ).

Reported symptoms and bronchodilator use correlated with neither the objective measures of asthma severity (BHR, PEFR variability, and pulmonary function; $p>0.1$ ) nor the exposure to mite allergens in mite-sensitive patients.

In the group of patients with negative skin test responses to mites, no correlation was found between allergen exposure and BHR, amplitude percent mean PEFR, and percent predicted $\mathrm{FEV}_{1}$ $(p>0.5)$.

\section{DISCUSSION}

BHR is a characteristic feature of most patients with asthma and can be objectively defined and measured by methacholine (or histamine) bronchoprovocation. The frequency of asthma symptoms and medication use correlates with the severity of BHR, and a number of factors can contribute to BHR and trigger asthma attacks. ${ }^{18,19}$ Among these, exposure to indoor allergens, particularly those of house dust mites, can play an important 

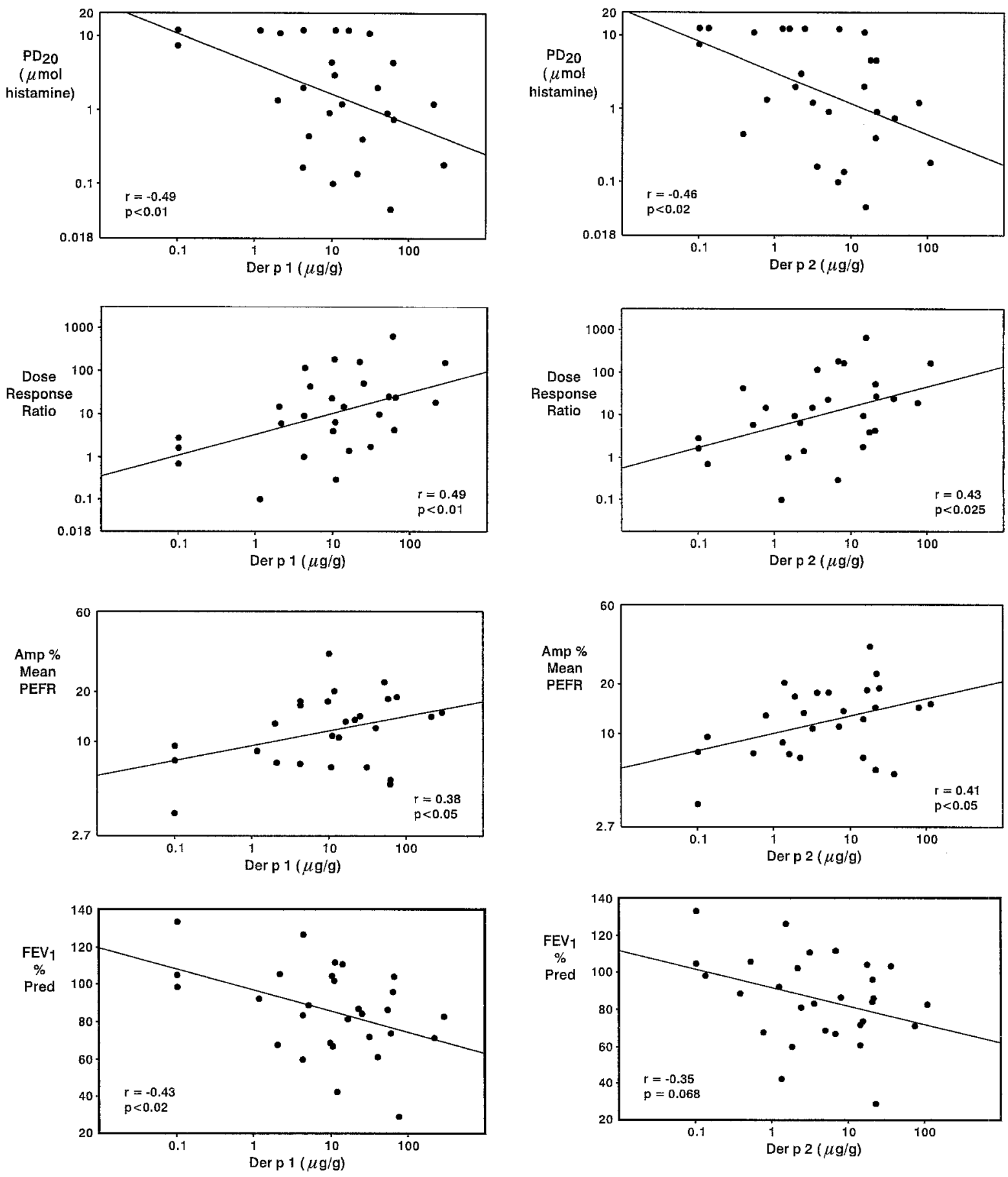

FIG. 3. Correlation between Der $p 1$ concentration in beds and measures of disease activity: $\mathrm{PD}_{20}$ ( $\mu$ mol methacholine; $n=27$ ), DRR (percent drop in $\mathrm{FEV}_{1} / \mu \mathrm{mol}$ methacholine; $n=27)$, amplitude percent mean PEFR ( $n=27)$, and percent predicted $\mathrm{FEV}_{1}(n=29)$. Amp, Amplitude.

role in both primary sensitization and later development of asthma. ${ }^{20}$

The level of BHR is arguably the best indirect indicator of severity of the underlying inflamma-

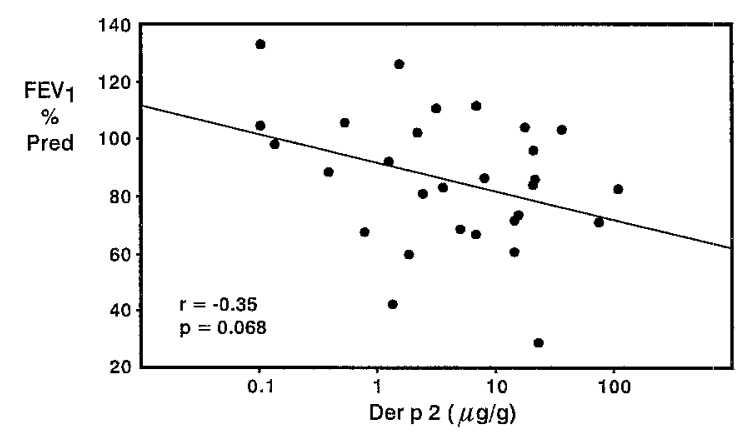

FIG. 4. Correlation between Der p 2 concentration in beds and measures of disease activity: $\mathrm{PD}_{20}$ ( $\mu$ mol methacholine; $n=27$ ), DRR (percent drop in $\mathrm{FEV}_{1} / \mu \mathrm{mol}$ methacholine; $n=27)$, amplitude percent mean PEFR $(n=27)$, and percent predicted $\mathrm{FEV}_{1}(n=29)$. Amp, Amplitude.

tory process, which is a key feature of asthmatic airways. ${ }^{21}$ Therefore the degree of BHR may indirectly reflect the severity of the disease process in asthma. If allergens play a role in the maintenance of airway inflammation, then a quantitative rela- 
tionship between the levels of exposure and BHR would be predicted. A study on exposure to mite allergen and pediatric hospital admissions has shown that most children admitted to the hospital because of exacerbation of asthma were both sensitized and exposed to mite allergen and also suggested that continued exposure to higher concentrations of mite allergen may be associated with the risk for readmission. ${ }^{22}$ The results of this study support this suggestion, because in the group of patients with mite-sensitive asthma, those with demonstrable BHR were exposed to significantly higher levels of both group 1 and group 2 allergens than those without demonstrable BHR. The proportion of patients with $\mathrm{PD}_{20}$ greater than 12.25 $\mu \mathrm{mol}$ methacholine is comparable to that of previous studies examining airway responsiveness to methacholine and histamine in patients with mild to moderate asthma, ${ }^{18}$ because a smaller proportion of subjects without previous experience of forced expiratory maneuvers will have a $\mathrm{PD}_{20}$ that can be estimated. ${ }^{23}$ Expressing the results as DRR enabled us to calculate the level of reduction in pulmonary function per unit of methacholine, and it is noteworthy that all methacholine nonreactors showed some level of decline in $\mathrm{FEV}_{1}$ after the last dose of methacholine. Furthermore, the diagnosis of asthma in all participants was established by their family practitioner on the basis of reversibility after administration of bronchodilators or PEFR variability over a period of 2 weeks. We therefore believe that our sample is representative for the population of patients with asthma diagnosed and followed up in family practice. Thus a high level of allergen exposure is not only associated with the risk of exacerbation but also with increased BHR in patients with stable asthma treated outside the hospital setting.

Allergen exposure has been related to disease severity. In one of the first studies relating dust mites to asthma, visits to the hospital by patients with mite-sensitive asthma correlated with mite growth curves in their homes. ${ }^{24}$ After a controlled or seasonal exposure to allergens, sensitized subjects experience an increase in BHR. ${ }^{25,26}$ Exposure to Alternaria allergen has been shown to be a risk factor for sudden respiratory arrest in patients with asthma. ${ }^{27}$ When patients with mite-sensitive asthma move to a higher altitude or the mite-free environment of a hospital, their asthma improves. ${ }^{28,29}$ House dust mite avoidance in the home is associated with symptomatic improvement and reduction in BHR and medication use. ${ }^{30}$ However, showing the direct relationship between al- lergen exposure and disease activity has always been difficult because of a number of possible confounding factors. Patients with asthma are often sensitized and exposed to more than one allergen. In our group, 30 patients had positive skin test responses to grass pollens, 29 to cats, and 16 to tree pollens. To avoid potential confounding by pollen, we designed the timing of the study to coincide with the end of the grass and tree pollen seasons (August to September). During the study period, the pollen counts obtained from the local pollen station remained very low and were unlikely to have influenced the results. Furthermore, individual plots of PEFR variability against grass and tree pollens in pollen-sensitive subjects showed no association (because of very low pollen counts). An effort was made to identify cat-sensitive cat owners, because exposure to cat allergen in this group of patients would be a major confounding factor. Only one subject was identified in this group and was unable to undergo bronchial challenge because of consistently low $\mathrm{FEV}_{1}(<50 \%)$. Mean household exposure to cat allergen Fel $\mathrm{d} 1$ in patients with positive skin test responses to both mites and cats was $1.3 \mu \mathrm{g} / \mathrm{gm}$ of fine dust, the levels that are usually found in homes without a cat. ${ }^{31}$ It is unlikely that exposure to cat allergen at these levels was a significant confounding factor in the analysis of mite allergen exposure-response relationship in asthma activity. Another important factor that can influence the level of BHR is viral infection..$^{32}$ By doing the study in the late summer, we missed the main season of viral respiratory tract infections, and therefore only two patients dropped out of the study because of respiratory tract infections. Subjects were asked to keep daily records of respiratory symptoms and bronchodilator use by rating the severity of each of three symptoms (wheeze, cough, and shortness of breath) on a visual analog scale from "none" to "worst ever" (10 cm lines) and to record the number of puffs of bronchodilator medication used. Neither reported symptoms nor bronchodilator use correlated with objective measures of asthma severity. This may be because there is considerable variability among individual perception of asthma severity and use of visual analog scales. Symptom scores and medication use are therefore more appropriate to longitudinal studies.

Theoretically, measurement of airborne allergen should be more representative of exposure than the levels in reservoir dust. ${ }^{33}$ There is still considerable debate about whether the level of mite allergen in settled dust from allergen reservoirs or 
the level in ambient air is a better index of exposure. ${ }^{34}$ We failed to detect airborne mite allergens (Der p 1 or Der p 2) in all but two samples. This confirms that airborne sampling with current techniques has serious limitations as a routine method for the assessment of house dust mite allergen exposure. ${ }^{33}$ In our laboratory we are able to detect airborne mite allergens only after vigorous disturbance (e.g., vacuuming without a bag and filter).

The results of reservoir sampling were therefore used, and like Sporik et al., ${ }^{4}$ who reported the highest Der $\mathrm{p} 1$ level from different parts of the house, we considered exposure to be the highest concentration from samples collected in beds. The appropriate model to relate exposure information to dose, and this relationship to response, is not known. ${ }^{8}$ We therefore decided to use a similar model of dose-response assessment, which has already been used in the analysis of exposure to mite allergen and the risk of allergic sensitization. ${ }^{8}$ A linear relationship in exposure-response was assumed. ${ }^{8}$ We have previously reported the absence of seasonal variation in Der $\mathrm{p} 1$ level in the area, ${ }^{35}$ making a single exposure measurement an appropriate measure of dose. Our results suggest that in mite-sensitive patients, the level of exposure to mite allergens has a major influence on severity and clinical activity of asthma. A similar correlation was seen for three measures of disease severity (BHR, PEFR variability, and pulmonary function) in subjects with positive skin test responses to mites, but no relationship was seen in those who had negative skin test responses. These results are in agreement with recent observations by Marks et al. ${ }^{36}$ that Der $\mathrm{p} 1$ concentration in beds correlates with the severity of BHR and asthma symptoms. Van der Heide et al. ${ }^{37}$ have recently suggested that even small changes in exposure to mite allergens are associated with changes in airway responsiveness. The results of this study support this suggestion and question whether even relatively modest reduction in exposure could be of some benefit to the patient. However, if the assumption of a linear dose-response relationship is correct, a "no effect" level for exposure to mite allergens would not be able to be identified. (This threshold is known as the No Observed Adverse Effect Level..$^{38}$ ) This would imply that there is no threshold concentration that could be generally applicable to every individual and below which no adverse effect on airway responsiveness or variability in pulmonary function would occur. There is probably considerable variability among individu- als in the magnitude of response to the same levels of allergen exposure. Thus in a group of individuals with similar levels of $\operatorname{IgE}$ antibodies, some will experience symptoms only if they are exposed to high levels of allergens, whereas others require very low exposure to maintain symptoms; that is, the level of exposure necessary to induce and maintain airway inflammation, BHR, and symptoms varies over a wide range. ${ }^{39}$

In conclusion, in patients with mite-sensitive asthma there is a dose-response relationship between the level of exposure to Group 1 and Group 2 house dust mite allergen and disease severity and clinical activity (as measured by level of BHR, PEFR variability, and pulmonary function testing).

We thank the members of Brookvale and Appleton G.P. surgeries for their valuable assistance in carrying out this study.

\section{REFERENCES}

1. Burr ML, Butland BH, King S, Vaughan-Williams E. Changes in asthma prevalence: two surveys 15 years apart. Arch Dis Child 1989;64:1452-6.

2. Smith JM, Disney ME, Williams JD, Goels ZA. Clinical significance of skin reactions to mite extracts in children with asthma. BMJ 1969;1:723-6.

3. Rowntree S, Cogswell JJ, Platts-Mills TAE, et al. Development of $\operatorname{IgE}$ and $\operatorname{IgG}$ antibodies to food and inhalant allergens in children at risk of atopic disease. Arch Dis Child 1985;60:727-35.

4. Sporik R, Holgate S, Platts Mills TAE, Cogswell J. Exposure to house dust mite allergen (Der p I) and the development of asthma in childhood. N Engl J Med 1990;323:502-7.

5. Dowse GK, Turner KJ, Stewart GA, Alpers MP, Woolcock AJ. The association between Dermatophagoides mites and the increasing prevalence of asthma. J Allergy Clin Immunol 1985;75:75-83.

6. Charpin D, Kleisbauer JP, Lanteaume A, et al. Asthma and allergy to house dust mites in population living in high altitudes. Chest 1988;93:758-61.

7. Sporik R, Ingram JM, Price W, Sussman JH, Honsinger RW, Platts Mills TAE. Association of asthma with serum $\operatorname{IgE}$ and skin-test reactivity to allergens among children living at high altitude: tickling the dragon's breath. Am J Respir Crit Care Med 1995;151:1388-92.

8. Pope AM, Patterson R, Burge H, eds. Indoor allergens. Assessing and controlling adverse health effects. Washington DC: National Academy Press, 1993.

9. Sporik R, Chapman MD, Platts Mills TAE. House dust mite exposure as a cause of asthma. Clin Exp Allergy 1992;22:897-906.

10. Andersen I, Korsgaard J. Asthma and the indoor environment: assessment of health implications of high indoor relative humidity. Environment International 1986;12: $121-7$.

11. Tovey ER, Chapman MD, Wells CW, Platts Mills TAE. The distribution of house dust mite allergen in the houses of patients with asthma. Am Rev Respir Dis 1981;124: 630-5. 
12. Kivity S, Solomon A, Soferman R, Schwarz Y, Mumcuoglu KY, Topilsky M. Mite asthma in childhood: a study of the relationship between exposure to house dust mites and disease activity. J Allergy Clin Immunol 1993;91:844-9.

13. Yan K, Salome C, Woolcock AJ. Rapid method of measurement of bronchial hyperreactivity. Thorax 1983;38: $760-5$.

14. O'Connor G, Sparrow D, Taylor D, Segal M, Weiss S. Analysis of dose-response curves to methacholine. An approach suitable for population studies. Am Rev Respir Dis $1987 ; 136: 1412-7$.

15. Higgins BG, Britton JR, Chinn S, et al. The distribution of peak expiratory flow variability in a population sample. Am Rev Respir Dis 1989;140:1368-72.

16. Chapman MD, Hayman PW, Wilkins SR, Brown MB, Platts Mills TAE. Monoclonal immunoassays for the major dust mite (Dermatophagoides) allergens, $\operatorname{Der} p$ I and $\operatorname{Der} f \mathrm{I}$ and quantitative analysis of the allergen content of mite and house dust extracts. J Allergy Clin Immunol 1987;80:184-94.

17. Ovsiannikova IG, Vailes LD, Li Y, Heyman PW, Chapman MD. Monoclonal antibodies to group II Dermatophagoides spp. allergens: murine immune response, epitope analysis, and development of a two-site ELISA. J Allergy Clin Immunol 1994;94:537-47.

18. Juniper EF, Frith PA, Hargreave FE. Airway responsiveness to histamine and methacholine: relationship to minimum treatment to control symptoms of asthma. Thorax 1981;36:575-9.

19. Vervloet D, Charpin D, Haddi E, et al. Medication requirements and house dust mite exposure in mite-sensitive asthmatics. Allergy 1991;46:554-8.

20. Platts Mills TAE. Allergens and asthma. Allergy Ptoc 1990;11:269-71.

21. Kelly CA, Stenton SC, Ward C, Bird G, Hendrick DJ, Walters EH. Lymphocyte subsets in bronchoalveolar lavage fluid obtained from stable asthmatics, and their correlations with bronchial responsiveness. Clin Exp Allergy 1989;19; $169-75$.

22. Sporik R, Platts Mills TAE, Cogswell JJ. Exposure to house dust mite allergen of children admitted to hospital with asthma. Clin Exp Allergy 1993;23:740-6.

23. Chinn S, Britton JR, Burney PGJ, Tattersfield AE, Papacosta AO. Estimation and repeatability of the response to inhaled histamine in a community survey. Thorax 1987:42:45-52.

24. Voorhorst R, Spieksma FTM, Varekamp H, Leupen MJ, Lyklema AW. The house dust mite (Dermatophagoides pteronyssinus) and the allergens it produces: identity with the house dust allergen. J Allergy 1967;39:325-39.

25. Aalberse R, Kauffman HF, Koeter GH, Postma DS, De Vries K, De Monchy JGR. Dissimilarity in methacholine and adenosine $5^{\prime}$-monophosphate responsiveness 3 and 24 hours after allergen challenge. Am Rev Respir Dis 1991; $144: 352-7$
26. Cockroft DW, Ruffin RE, Dolovich J, Hargreave FE. Allergen-induced increase in non-allergic bronchial reactivity. Clin Allergy 1977;7:503-13.

27. O'Hallaren MT, Yunginger JW, Offord KP, et al. Exposure to an aeroallergen as a possible precipitating factor in respiratory arrest in young patients with asthma. N Engl J Med 1991;324:359-63.

28. Boner AL, Niero E, Antolini I, Valletta EA, Guburro D. Pulmonary function and bronchial hyperreactivity in asthmatic children with house dust mite allergy during prolonged stay in Italian Alps (Misurina $1756 \mathrm{~m}$ ). Ann Allergy 1985;54:42-5.

29. Platts Mills TAE, Tovey ER, Mitchell EB, Moszoro H, Nock P, Wilkins P. Reduction of bronchial hyperreactivity following prolonged allergen avoidance. Lancet 1982;2: 675-8.

30. Colloff MJ, Ayers J, Carswell F, et al. The control of allergens of dust mites and domestic pets: a position paper. Clin Exp Allergy 1992;22 (suppl 2):1-28.

31. Wood RA, Eggleston PA, Lind P, et al. Antigenic analysis of household dust samples. Am Rev Respir Dis 1988;137: 358-63.

32. Minor TE, Dick EC, DeMeo AN, Oullette JJ, Cohen M, Reed CE. Viruses as precipitants of asthmatic attack in children. JAMA 1974;227:292-8.

33. Platts Mills TAE, Thomas W, Aalberse RC, Vervloet D, Chapman MD. Dust mite allergens and asthma: report of a second international workshop. J Allergy Clin Immunol 1993;89:1046-57.

34. Price JA, Pollock J, Little SA, Longbottom JL, Warner JO. Measurement of airborne mite allergen in homes of asthmatic children. Lancet 1990;336:895-7.

35. Kalra S, Crank P, Hepworth J, Pickering CAC, Woodcock A. Absence of seasonal variation in concentration of the house dust mite allergen Der p I in South Manchester homes. Thorax 1992;47:928-33.

36. Marks G, Tovey E, Woolcock A. In subjects with asthma the concentration of Der p I in beds correlates with the severity of bronchial hyperresponsiveness and symptoms [Abstract]. Am Rev Respir Dis 1993;147:A458.

37. Van der Heide S, de Monchy JGR, de Vries K, Bruggink TM, Kauffman HK. Seasonal variation in airway hyperresponsiveness and natural exposure to house dust mite allergens in patients with asthma. J Allergy Clin Immunol 1994;93:470-5.

38. Shoaf CR. Current assessment practices for noncancer end points. Environ Health Perspect 1991;95:111-9.

39. Platts-Mills TAE, Sporik RB, Ward GW, Heyman PW, Chapman MD. Dose-response relationship between asthma and exposure to indoor allergens. In: Johansson SGO, ed. Progress in allergy and clinical immunology. Seattle: Hogrefe \& Huber Publishers, 1995:90-6. 